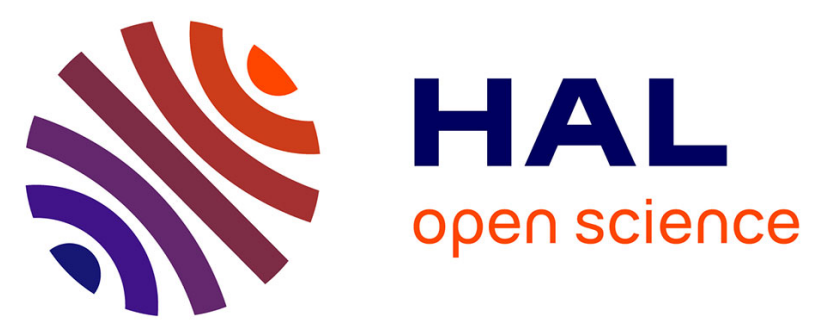

\title{
Diarylethene Self-Assembled Monolayers: Cocrystallization and Mixing-Induced Cooperativity Highlighted by Scanning Tunneling Microscopy at the Liquid/Solid Interface
}

Denis Frath, Takeshi Sakano, Yohei Imaizumi, Soichi Yokoyama, Takashi Hirose, Kenji Matsuda

\section{To cite this version:}

Denis Frath, Takeshi Sakano, Yohei Imaizumi, Soichi Yokoyama, Takashi Hirose, et al.. Diarylethene Self-Assembled Monolayers: Cocrystallization and Mixing-Induced Cooperativity Highlighted by Scanning Tunneling Microscopy at the Liquid/Solid Interface. Chemistry - A European Journal, 2015, 21 (32), pp.11350-11358. 10.1002/chem.201500804 . hal-01916046

\author{
HAL Id: hal-01916046 \\ https://hal.science/hal-01916046
}

Submitted on 16 Nov 2018

HAL is a multi-disciplinary open access archive for the deposit and dissemination of scientific research documents, whether they are published or not. The documents may come from teaching and research institutions in France or abroad, or from public or private research centers.
L'archive ouverte pluridisciplinaire HAL, est destinée au dépôt et à la diffusion de documents scientifiques de niveau recherche, publiés ou non, émanant des établissements d'enseignement et de recherche français ou étrangers, des laboratoires publics ou privés. 


\title{
Diarylethene Self-Assembled Monolayers: Cocrystallization and Mixing-Induced Cooperativity Highlighted by Scanning Tunnelling Microscopy at the Liquid/Solid Interface
}

\author{
Denis Frath, Takeshi Sakano, Yohei Imaizumi, Soichi Yokoyama, Takashi Hirose, and Kenji Matsuda*
}

\begin{abstract}
Stimulus control over 2-D multicomponent molecular ordering on surfaces is a key technology to realize advanced materials with stimuli-responsive surface properties. The 2-D molecular ordering formation along with photoisomerization was monitored by STM at octanoic acid/HOPG interface for the synthesized amide-containing diarylethene, which underwent photoisomerization between open- and closed-ring isomers and also side reaction to give annulated isomer. By the analysis of concentration dependence of surface coverage, the nucleation equilibrium constant $\left(K_{n}\right)$ and the elongation equilibrium constant $\left(K_{\mathrm{e}}\right)$ were determined using cooperative model at the liquid/solid interface. It was found that the annulated isomer has very large equilibrium constant which explains the predominantly observed ordering of the annulated isomer. It was also found that the presence of the closed-ring isomer induces cooperativity in the formation of the molecular ordering of the open-ring isomer. The quantitative analysis of the ordering formation using cooperative model provided a new viewpoint toward 2-D multicomponent molecular ordering formation.
\end{abstract}

\section{Introduction}

Control over molecular nanostructure has become of first importance in a bottom-up strategy to elaborate functionalized surfaces for electronic devices. ${ }^{[1]}$ In this context the study of the self-assembled monolayers (SAM) of organic building blocks on surfaces such as $A u(111)$ or highly oriented pyrolytic graphite (HOPG) has been the subject of intense research. ${ }^{[2-16]}$ Twodimensional (2-D) supramolecular self-assembly can be efficiently characterized by scanning tunneling microscopy (STM) at the liquid/solid interface with single-molecule resolution, ${ }^{[17]}$ revealing influences of various factors such as concentration, ${ }^{[18-20]}$ temperature,${ }^{[20-22]}$ electric pulse,${ }^{[23-25]}$ light, ${ }^{[25]}$ or addition of guests. ${ }^{[26,27]}$ In order to use light as an external trigger, a photoresponsive material is required. Among the organic photochromes, diarylethenes are very appealing due to the high thermal stability of both the open- and closed-ring isomers and their high fatigue resistance. ${ }^{[28-30]}$

[*] Dr. D. Frath, Dr. T. Sakano, Y. Imaizumi, S. Yokoyama, Dr. T. Hirose, Prof. K. Matsuda

Department of Synthetic Chemistry and Biological Chemistry

Graduate School of Engineering, Kyoto University

Katsura, Nishikyo-ku, Kyoto 615-8510, Japan

E-mail: kmatsuda@sbchem.kyoto-u.ac.jp
We have previously reported a light-induced switching between two different 2-D molecular orderings by isomerization of a diarylethene bearing pyrenyl group. ${ }^{[31]}$ Herein we describe the properties of another diarylethene with three isomers $(\mathbf{1 0}, \mathbf{1 c}$, and 1a, Fig. 1) that form stable 2-D molecular orderings on HOPG surface. A quantitative analysis of the cooperativity in the formation of their 2-D orderings and mixing of components in an ordering will be discussed based on concentration dependence of surface coverage for mono- and bi-component systems.

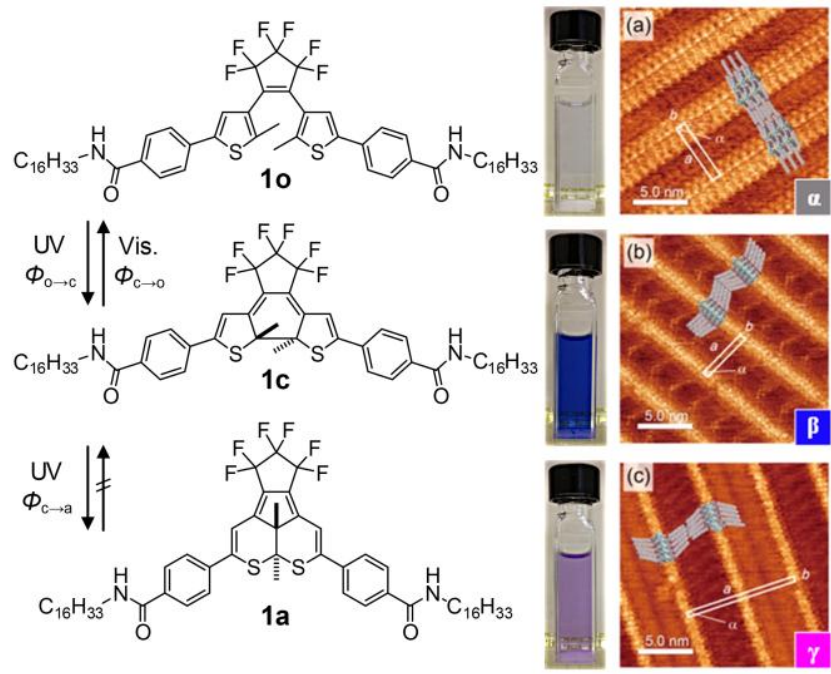

Figure 1. Chemical structures and STM images of (a) the open-ring isomer 10 (ordering $\alpha$ ), (b) the closed-ring isomer 1c (ordering $\beta$ ), and (c) the annulated isomer 1a (ordering $\mathrm{y}$ ). See ref 32 for details of the orderings.

\section{Results and Discussion}

\section{Synthesis and photophysical properties}

A diarylethene was designed to have long alkyl chains and amides group for stabilization of SAM on HOPG. ${ }^{\left[{ }^{32]}\right.}$ The openring isomer 10 was obtained by a two steps one-pot reaction starting from the corresponding bromo-substituted diarylethene with a yield of $94 \%$. The closed-ring isomer 1c was prepared by a classic photoreaction carried out by UV light irradiation to a solution of 10 in ethyl acetate for $1 \mathrm{~h}$. The isolated yield of compound 1c was $72 \%$. A long-time irradiation (34 h) to a solution of 10 with UV light afforded the annulated isomer 1a with a $17 \%$ yield.

Absorption spectra were recorded for each isomer in octanoic acid (OA) since this solvent was used in STM 
measurements (Figure 2). The shape and magnitude of the absorption spectra were well reproduced by time-dependent density functional theory (TD-DFT) calculations at the B3LYP/6$311 \mathrm{~g}(2 \mathrm{~d}, \mathrm{p}) / / \mathrm{B} 3 \mathrm{LYP} / 6-31 \mathrm{~g}(\mathrm{~d})$ level (See Figure S1-S5 in Supporting Information).

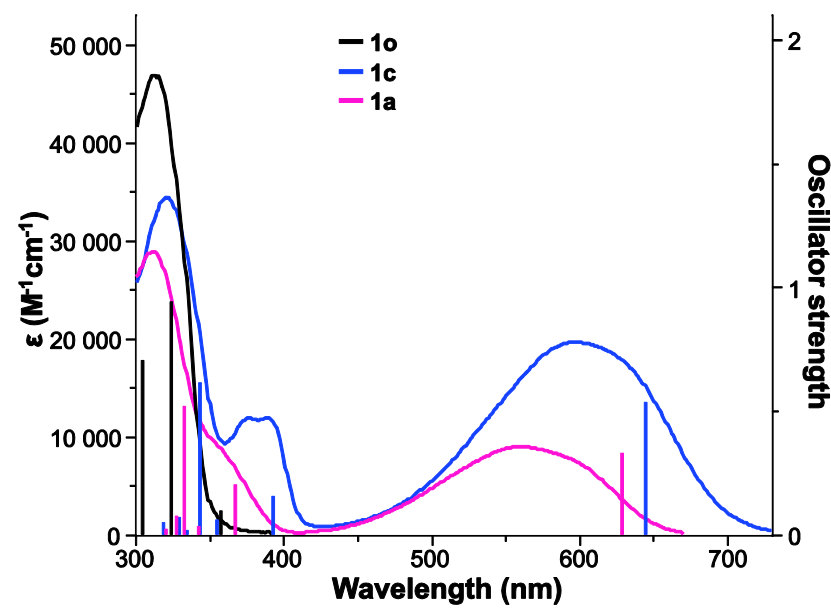

Figure 2. Absorption spectra of compounds 10 (black), 1c (blue), and 1a (pink) in octanoic acid and theoretical oscillator strengths calculated by TDDFT.

The ratio of the photoreaction quantum yields of diarylethene 1 for the cyclization $\left(\Phi_{\mathrm{o} \rightarrow \mathrm{c}}\right)$, cycloreversion $\left(\Phi_{\mathrm{c} \rightarrow \mathrm{O}}\right)$, and annulation reactions $\left(\Phi_{\mathrm{c} \rightarrow \mathrm{a}}\right)$ was estimated from the time evolution of absorption spectra upon UV irradiation $\left(\lambda_{\text {irrad }}=365 \mathrm{~nm}\right)$ in OA (Figure $\mathrm{S} 6$ in Supporting Information). Figure 3 shows the temporal change of concentration over irradiation time obtained by full-spectrum fitting of the time evolution of absorption spectra shown in Figure S6 in Supporting Information, using the spectra of the three isomers shown in Figure 2. The temporal differentiation of concentration of each isomer can be described by the reaction quantum yields $(\Phi)$ and molar absorption coefficients $(\varepsilon)$ as follows:

$\frac{d[\mathbf{1 o}]}{d t}=\left(\varepsilon_{\mathrm{c}}[\mathbf{1} \mathbf{c}] \Phi_{\mathrm{c} \rightarrow \mathrm{o}}-\varepsilon_{\mathrm{o}}[\mathbf{1 o}] \Phi_{\mathrm{o} \rightarrow \mathrm{c}}\right) \frac{\left(1-10^{-\mathrm{Al} l}\right) I_{0}}{\mathrm{~A}}$

$\frac{d[\mathbf{1} \mathbf{c}]}{d t}=\left(\varepsilon_{0}[\mathbf{1 0}] \Phi_{\mathrm{o} \rightarrow \mathrm{c}}-\varepsilon_{\mathrm{c}}[\mathbf{1} \mathbf{c}] \Phi_{\mathrm{c} \rightarrow \mathrm{o}}-\varepsilon_{\mathrm{c}}[\mathbf{1} \mathbf{c}] \Phi_{\mathrm{c} \rightarrow \mathrm{a}}\right) \frac{\left(1-10^{-\mathrm{A} l}\right) I_{0}}{\mathrm{~A}}$

$\frac{d[\mathbf{1} \mathbf{a}]}{d t}=\left(\varepsilon_{\mathrm{c}}[\mathbf{1} \mathbf{c}] \Phi_{\mathrm{c} \rightarrow \mathrm{a}}\right) \frac{\left(1-10^{-\mathrm{A} l}\right) I_{0}}{\mathrm{~A}}$ where $\mathrm{A}=\varepsilon_{\mathrm{o}}[\mathbf{1 o}]+\varepsilon_{\mathrm{c}}[\mathbf{1} \mathbf{c}]+\varepsilon_{\mathrm{a}}[\mathbf{1} \mathbf{a}]$

where $\varepsilon_{0}, \varepsilon_{\mathrm{c}}$, and $\varepsilon_{\mathrm{a}}$ are the molar absorption coefficients of each isomer at the irradiation wavelength, $/$ is the optical path length, and $l_{0}$ is the intensity of irradiation. To obtain a set of simulated curves of best fit, the ratio of three reaction quantum yields were optimized by non-linear regression analysis in every steps of which the simultaneous differential equations were numerically solved with experimentally determined initial parameters. The resulting ratio $\Phi_{\mathrm{o} \rightarrow \mathrm{c}}: \Phi_{\mathrm{c} \rightarrow \mathrm{o}}: \Phi_{\mathrm{c} \rightarrow \mathrm{a}}$ was 1:0.047:0.001. The photoreaction quantum yield for the annulation reaction $\left(\Phi_{\mathrm{c} \rightarrow \mathrm{a}}\right)$ was only $2.1 \%$ of the cycloreversion quantum yield $\left(\Phi_{\mathrm{c} \rightarrow \mathrm{O}}\right)$. When $\Phi_{\mathrm{o} \rightarrow \mathrm{c}}$ is assumed to be 0.59 as reported for a similar diarylethene derivative ${ }^{[33]} \Phi_{\mathrm{c} \rightarrow \mathrm{o}}$ and $\Phi_{\mathrm{c} \rightarrow \mathrm{a}}$ become $2.8 \times 10^{-2}$ and $6.0 \times 10^{-4}$, respectively.

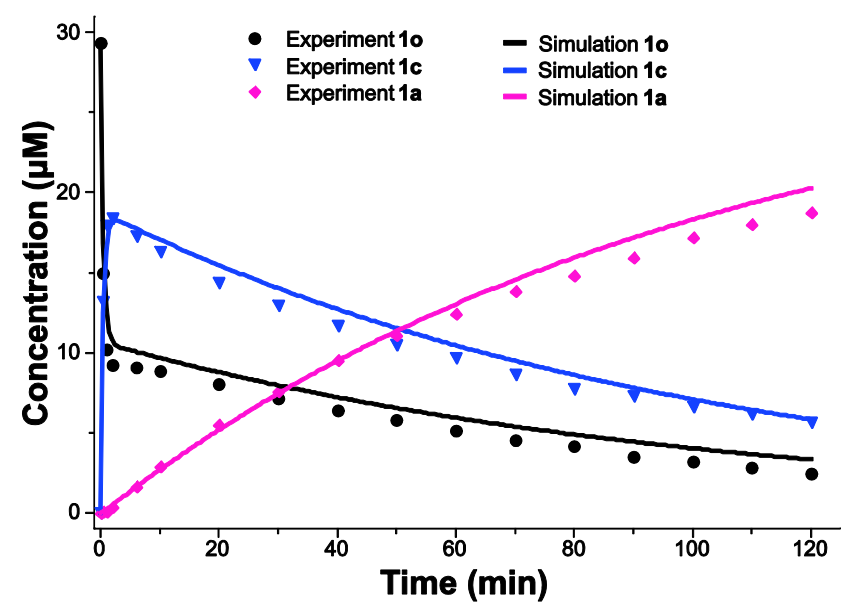

Figure 3. Evolution of the composition of the three isomers in octanoic acid upon UV irradiation $\left(\lambda_{\text {irrad }}=365 \mathrm{~nm},[10]_{t=0}=29.4 \mu \mathrm{M}, V=3.0 \mathrm{~mL}, I=1 \mathrm{~cm}\right)$.

\section{Scanning Tunnelling Microscopy}

As reported previously, compounds 10, 1c, and 1a form characteristic stripe-patterned orderings $(\alpha, \beta$, and $\gamma$, respectively) at the OA/HOPG interface (Figure 1). ${ }^{\left[{ }^{[2]} \text { It was }\right.}$ also reported that only ordering $\mathrm{Y}$, composed of compound 1a, was observed after irradiation with UV light on the surface, even if the annulated isomer is only a photochemical byproduct that is generated with the small photogeneration yield as mentioned above. ${ }^{[34]}$ Ordering $\beta$, formed by the main photoproduct 1c, was not observed after irradiating the surface with UV light.

In order to rationalize the reason for the favorable appearance of ordering $\mathrm{y}$ upon in situ UV irradiation, we investigated the concentration dependence of the surface coverage using STM (Figure 4). Compound 10 showed a gradual increase of the surface coverage as concentration in solution phase increases. The critical concentration, at which a saturated adsorption was observed, was around $30 \mu \mathrm{M}$ for 10 . The closed-ring isomer 1c presented a brutal increase of the surface coverage at approximately the same critical concentration as the open-ring isomer $(\sim 30 \mu \mathrm{M})$. The annulated isomer 1a also showed a sharp increase of the surface coverage, and its critical concentration appeared at a lower concentration $(\sim 15 \mu \mathrm{M})$. An interesting feature of compound 1a is that the observed surface coverage was close to the theoretical maximum, meaning that almost all molecules available in solution are involved in the construction of ordering $Y$. This suggests a very high affinity of 1 a for the HOPG surface.

Once saturated adsorption at the interface was reached, an increase in concentration resulted in the formation of aggregates and/or multilayers on the surface for each of the isomers (Figure S15, S24 and S31 in Supporting Information). At concentrations less than critical concentration, the domain 
size of ordered area on HOPG is usually larger than the scan size of STM $\left(\sim 200 \times 200 \mathrm{~nm}^{2}\right)$. A part of a large domain was typically observed in some images, while no ordering was observed in the others. This fact brings about a large dispersion of surface coverage data and is inevitably associated with large error bars even if more data are collected (Figure 4). The stripepatterned orderings $\alpha, \beta$, and $y$ were thermodynamically stable and no polymorph was observed in the range of concentrations used in this study.

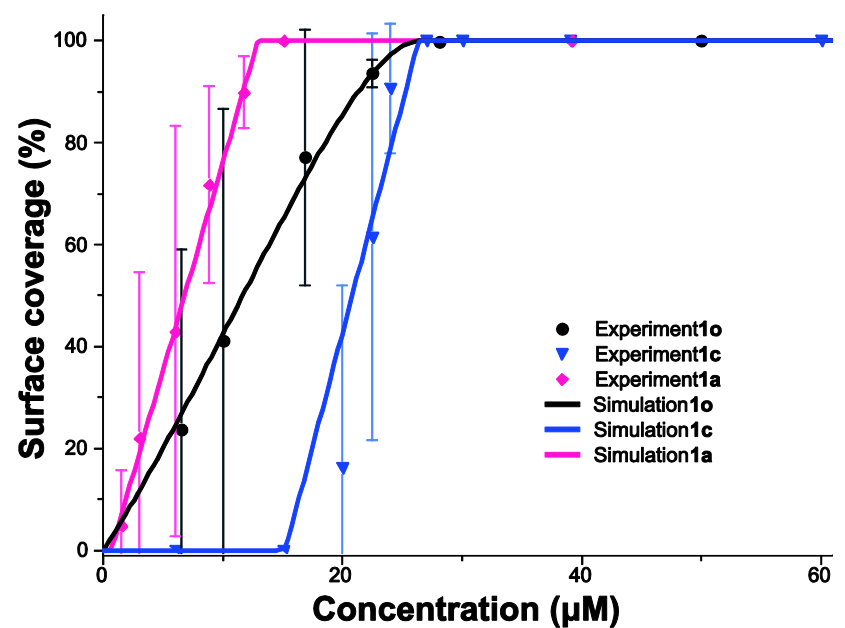

Figure 4. Concentration dependence of the surface coverage of 10 (black), 1c (blue), and 1a (pink) at the OA/HOPG interface. See Supporting Information for details of observed STM images at different concentration.

\section{Adsorption parameters (mono-component systems)}

Although the critical concentrations for 10 and 1c are almost the same, the steepness of the concentration dependence is obviously different for the two isomers. Therefore, critical concentration alone is not sufficient to characterize the process of the ordering formation. Inspired by cooperative supramolecular polymerization in solution, ${ }^{[35,36]}$ an equilibrium model at the liquid/solid interface has been recently developed by our group. ${ }^{[37]}$ The model considers two different equilibrium constants, nucleation $\left(K_{n}\right)$ and elongation constants $\left(K_{e}\right)$, therefore it takes into account the intermolecular interactions between neighbouring molecules on the substrate. It is noted that the experimental concentration dependence of surface coverage was well reproduced by using the two parameters (Figure 4).

According to this model, the fractional coverage $\theta$ can be described as follows:

$$
\theta=(1-\theta) \frac{\sigma K_{e}\left(c_{t}-\alpha \theta\right)}{\left\{1-K_{e}\left(c_{t}-\alpha \theta\right)\right\}^{2}}, \text { where } \alpha=\frac{A_{s u b}}{L N_{A} S}
$$

where $\sigma$ is the degree of cooperativity defined as the ratio $K_{n} / K_{\mathrm{e}}$, $c_{t}$ is the total concentration of the component, $A_{\text {sub }}$ is the total area of substrate, $L$ is the volume of supernatant solution, $S$ is the surface area occupied by one molecule, and $N_{\mathrm{A}}$ is the
Avogadro constant. Since molecular ordering formation at the liquid/solid interface is a process of 2-D crystal growth, it should comply with a cooperative model, in which $K_{\mathrm{n}}$ is smaller than $K_{\mathrm{e}}$ $(\sigma<1)$.

The simulated curves that fit the best with experimental data are shown in Figure 4 (solid lines) and the adsorption parameters are summarized in Table 1. Experimental data for the open-ring isomer $\mathbf{1 0}$ were sufficiently reproduced by considering isodesmic adsorption in which nucleation and subsequent elongation steps have identical equilibrium constant $\left(K_{\mathrm{n}} \sim K_{\mathrm{e}}, \sigma \sim 1\right)$. The elongation constant of $1 \mathrm{c}\left(K_{\mathrm{e}}=6.6 \times 10^{4}\right.$ $\left.\mathrm{M}^{-1}\right)$ is comparable to that of $10\left(K_{\mathrm{e}}=6.8 \times 10^{4} \mathrm{M}^{-1}\right)$, whereas the nucleation constant of $1 \mathrm{c}\left(K_{\mathrm{n}}=6.6 \times 10^{-2} \mathrm{M}^{-1}\right)$ is almost six orders of magnitude less than that of the open-ring isomer 10 $\left(K_{n}=6.4 \times 10^{4} \mathrm{M}^{-1}\right)$. Thus, the steep rise in the concentration dependence for the closed-ring isomer $1 \mathrm{c}$ can be explained as a highly cooperative process $\left(\sigma \leq 10^{-6}\right)$.

\begin{tabular}{cccc}
\hline \multicolumn{4}{c}{ Table 1 Adsorption parameters of 10, 1c, and 1a on HOPG surface ${ }^{a}$} \\
\hline Compound & $K_{\mathrm{e}}\left(\mathrm{M}^{-1}\right)$ & $K_{\mathrm{n}}\left(\mathrm{M}^{-1}\right)$ & $\sigma$ \\
\hline 1o & $6.8 \times 10^{4}$ & $6.4 \times 10^{4}$ & 0.95 \\
1c & $6.6 \times 10^{4}$ & $\leq 6.6 \times 10^{-2}$ & $\leq 10^{-6} \mathrm{~b}$ \\
1a & $1.5 \times 10^{6}$ & $\leq 1.5$ & $\leq 10^{-6} \mathrm{~b}$
\end{tabular}

${ }^{a}$ simulated by the cooperative model on 2-D surface (mono-component systems) ${ }^{b}$ for values below $10^{-6}$, the curves are no longer significantly dependent on $\sigma$. Therefore, $\sigma$ less than $10^{-6}$ cannot be determined precisely.

The cooperative simulation $\left(K_{\mathrm{e}}=1.5 \times 10^{6} \mathrm{M}^{-1}, \sigma \leq 10^{-6}\right)$ gave the best-fitting curve for the experimental data of 1a, albeit the isodesmic simulation $\left(K_{\mathrm{e}}=1.0 \times 10^{6} \mathrm{M}^{-1}, \sigma=1\right)$ also gave an acceptable fitting (Figure $\mathrm{S} 8$ in $\mathrm{ESI}$ ). The result tells us that the simulated curves become less dependent on the degree of cooperativity $(\sigma)$ when the surface coverage is close to the theoretical maximum. Thus it was difficult to determine which process controls the formation of ordering $\mathrm{y}$. Since no major difference was observed for $\mathbf{1 a}$ between isodesmic and cooperative curves, cooperative model was applied for the subsequent calculations.

The favourable appearance of ordering $Y$ upon photoirradiation can be quantitatively explained by the large $K_{e}$ value for $1 \mathrm{a}\left(K_{\mathrm{e}} \geq 10^{6} \mathrm{M}^{-1}\right)$ that is associated with the very high affinity of the annulated isomer for the HOPG surface. The elongation constant for the annulated isomer 1a was even higher by almost two orders of magnitude $\left(K_{\mathrm{e}} \geq 10^{6} \mathrm{M}^{-1}\right)$ compared to 10 and 1c. Our model, using two adsorption parameters ( $K_{\mathrm{e}}$ and $\sigma$ ), is a very convenient tool for quantitative evaluation of the concentration dependence of ordering formation on 2-D surface. Moreover, surface coverage $\theta$ can be calculated at any concentration based on the two parameters.

\section{Pre-irradiation experiment}

For a careful investigation of fractional surface coverage in a multi-component system composed of different isomers, concentration of each isomer in solution should be precisely determined. A solution of the open-ring isomer $10(28.7 \mu \mathrm{M})$ was irradiated with UV light $\left(\lambda_{\text {irrad }}=365 \mathrm{~nm}\right)$ for 5,15 , and 45 minutes and the concentrations of each sample were determined by UVvis. spectroscopy. STM images were then acquired for the concentration-determined three samples that were irradiated 
before the deposition on HOPG (Figure 5). Respective fractional coverage observed for orderings $\alpha, \beta$, and $y$ are summarized in Table S1 in Supporting Information.
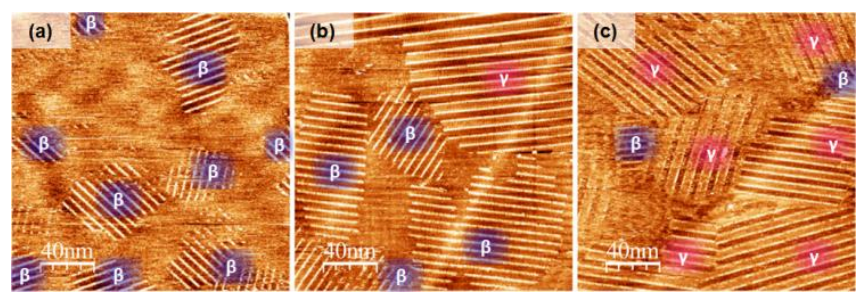

Figure 5. Representative STM images $\left(200 \times 200 \mathrm{~nm}^{2}\right)$ obtained by deposition of pre-irradiated solutions in $\mathrm{OA}\left(I_{\text {set }}=10 \mathrm{pA}, V_{\text {bias }}=-1.0 \mathrm{~V},[\mathbf{1 0}]_{t=0}=28.7 \mu \mathrm{M}\right)$. UV irradiation $\left(\lambda_{\text {irrad }}=365 \mathrm{~nm}\right.$ ) was conducted for (a) 5 , (b) 15 , and (c) $45 \mathrm{~min}$ prior to the deposition on HOPG. Concentration of each sample were precisely determined by UV-vis. spectroscopy (Table 4).

From the exact composition of the mixture, the fractional coverage $\theta$ for each isomer can be calculated based on the adsorption parameters determined above. The experimental fractional coverage of ordering $\mathrm{Y}\left(\theta_{\mathrm{\gamma}, \exp }=0,0.32\right.$, and 0.79 for the samples after UV irradiation for 3,15 , and $45 \mathrm{~min}$, respectively) was quite similar to the simulated values $\left(\theta_{\mathrm{r}, \mathrm{sim}}=\right.$ $0.09,0.26$, and 0.87 ), suggesting that the adsorption of 1a can be reproduced with mono-component parameters. However, experimental coverage for 10 and $1 \mathrm{c}\left(\theta_{\alpha, \exp }=0\right.$ for all samples; $\theta_{\beta, \exp }=0.35,0.18$, and 0.005$)$ were surprisingly different from the expectations $\left(\theta_{\alpha, \operatorname{sim}}=0.40,0.32\right.$, and $0.21 ; \theta_{\beta, \operatorname{sim}}=0.08,0.02$, and 0$)$; the experimental coverage for ordering $\beta$ was significantly higher than the predictions and ordering $\alpha$ was not observed in the experiment. These observations suggested that the open- and closed-ring isomers significantly influence each other during the formation of their 2-D orderings. As described in the next section, the experimental surface coverage was reproduced well by considering a mixing of the two isomers in the orderings $\alpha$ and $\beta$.

\section{Adsorption parameters (bi-component systems)}

In order to reveal the interaction between the two isomers 10 and 1c, concentration dependence of the surface coverage for the bi-component system was carefully investigated (Figure 6). Interestingly, only ordering $\beta$ was observed for the ratios (10/1c) of $0 / 100,37 / 63$, and $51 / 49$ (Figure $6 a$ ), and ordering $\alpha$ was solely observed for $78 / 22$ and $100 / 0$ (Figure $6 b$ ). Both orderings $\alpha$ and $\beta$ were observed simultaneously in a STM image for a narrow range of ratios such as $62 / 38 .{ }^{32}$ The simultaneous observation of the two orderings is also possible by drop-casting a concentrated solution of $1 \mathrm{c}$ to a pre-adsorbed solution of $1 \mathrm{o}^{\left[{ }^{[32]}\right.}$

The effect of the presence of 10 on the formation of ordering $\beta$ is clearly seen in Figure $6 a$, where we assumed that the ordering $\beta$ consists of only the closed-ring isomer and surface coverage of ordering $\beta$ is plotted against the concentration of 1c. If the formation of ordering $\beta$ is independent of the presence of the open-ring isomer 10, the same concentration dependence is expected for any ratio of isomers (10/1c). However, the critical concentration of 1c was obviously reduced from 26 to $21 \mu \mathrm{M}$ with increasing the fraction of 10 . At a given concentration of $\mathbf{1 c}$, the surface coverage of ordering $\beta$ is significantly increased by addition of 10. For instance, pure 1c at $15 \mu \mathrm{M}$ does not form any ordering. For the samples with the ratio of $37 / 63$ and $51 / 49$ containing $15 \mu \mathrm{M}$ of 1c, surface coverage of ordering $\beta$ reaches $25 \%$ and $56 \%$, respectively. This significant increase of surface coverage upon addition of 10 suggests that the ordering $\beta$ is likely a mixed crystal composed of the two isomers.

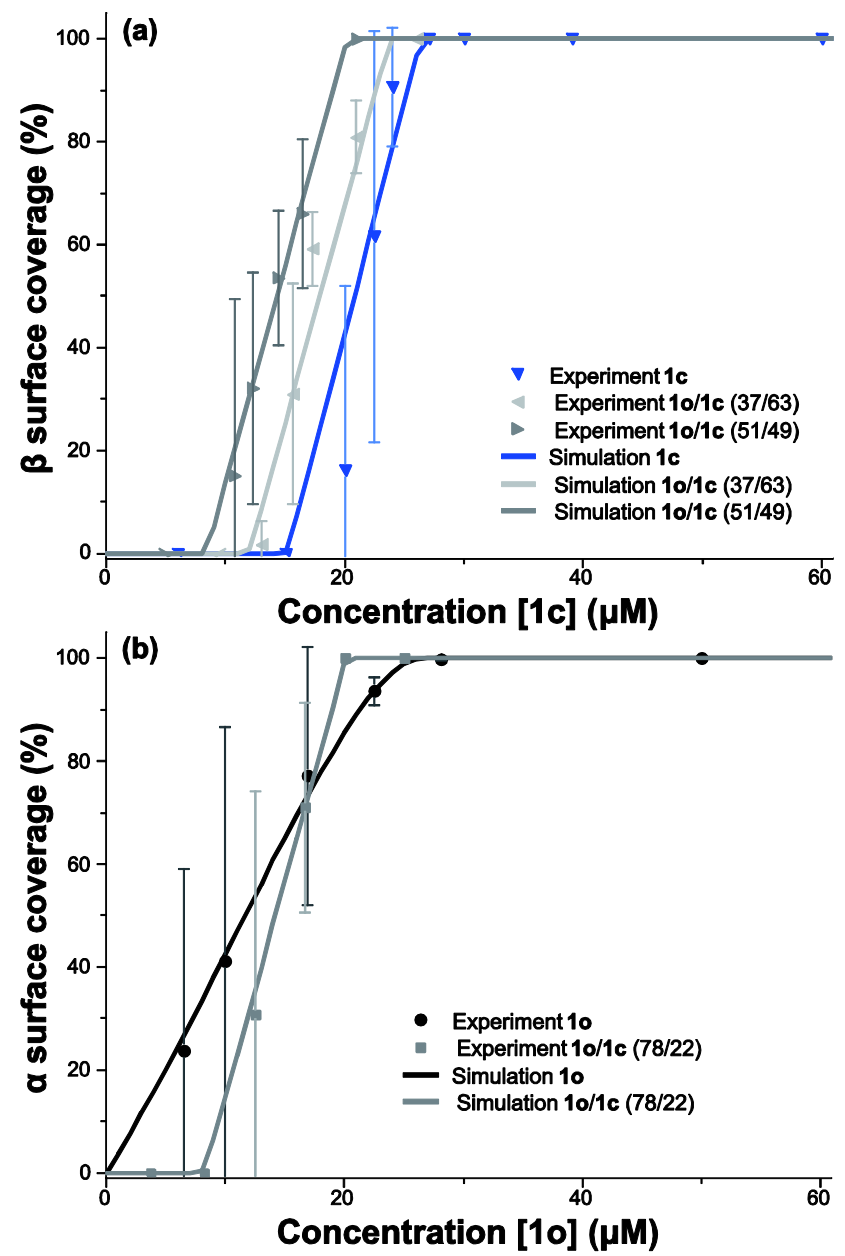

Figure 6. Concentration dependence of the surface coverage of (a) ordering $\beta$ for 1c and mixtures of 1o/1c (37/63 and 51/49), and that of (b) ordering $\alpha$ for 10 and a mixture of $10 / 1 c(78 / 22)$. Simulated curves (solid lines) were obtained with the adsorption parameters summarized in Table S2 in Supporting Information.

Since the mixing of two isomers in orderings $\alpha$ and $\beta$ was experimentally suggested, we assumed that the open- and closed-ring isomers cocrystalize on the 2-D surface and that both 10 and 1c contribute equally to the formation of orderings $\alpha$ and $\beta$. The surface coverage shown in Fig. 6 was plotted against the total concentration of the two isomers $[10+1 \mathrm{c}]$. The 
resulting curves are shown in Figure 7 and the corresponding adsorption parameters are summarized in Table 2.

Upon mixing the open-ring isomer 10 to the ordering $\beta$ that is mainly consisting of the closed-ring isomer $1 \mathrm{c}$, critical concentration increased from $26 \mu \mathrm{M}$ to $\sim 40 \mu \mathrm{M}$ for the ratio 10/1c of $51 / 49$ (Figure 7a). This is associated with the decrease of the elongation equilibrium constant $\left(K_{\mathrm{e}}\right)$ from $6.6 \times 10^{4}$ to 3.9 $\times 10^{4} \mathrm{M}^{-1}$ in the adsorption parameter (Table 2). The decrease of $K_{\mathrm{e}}$ is maybe because of a thermodynamic destabilization of ordering $\beta$ by the incorporation of the open-ring isomer 10 , which has a slightly different conformation to 1c. Upon mixing of 10 to ordering $\beta$, significant decrease of cooperativity (i.e., increase of $\sigma$ from less than $10^{-6}$ to $4.9 \times 10^{-3}$ ) was also observed, which originates from the increase of the nucleation equilibrium constant $\left(K_{\mathrm{n}}\right)$ (from $6.6 \times 10^{-2}$ to $1.9 \times 10^{2} \mathrm{M}^{-1}$ ). Because the open-ring isomer 10 has a higher nucleation value for the formation of ordering $\alpha\left(K_{n}=6.4 \times 10^{4} \mathrm{M}^{-1}\right)$, it would act as a seeding agent giving a nucleation point for subsequent elongation of ordering $\beta$.

Upon mixing the closed-ring isomer $\mathbf{1 c}$ to ordering $\alpha$ that is mainly composed of the open-ring isomer 10, a steep rise emerged in the concentration dependence of surface coverage (Figure $7 \mathrm{~b}$ ). In the adsorption parameters, the prominent increase of the cooperativity (i.e., $\sigma$ decreased from 0.95 to $6.0 \times$ $10^{-4}$ ) was observed (Table 2), which has already been mentioned on the analysis based only on concentration [10]. Thus, mixing-induced cooperativity in the formation of ordering a was also supported by the analysis of the total concentration [10 $+1 c]$.

The experimental surface coverage for the pre-irradiation experiment, shown in Figure 5, was reanalyzed by considering the mixing of the open- and the closed-ring isomers in the ordering $\alpha$ and $\beta$. In this analysis, the adsorption parameters for the ratio $37 / 63\left(K_{\mathrm{e}}=4.4 \times 10^{4} \mathrm{M}^{-1}, \sigma=5.2 \times 10^{-4}\right)$ were adopted since the experimental ratio is close to this value (i.e., $10 / 1 \mathrm{c}=$ $(35.4 \pm 1.3) /(64.6 \pm 1.3)$ for the samples irradiated for 5,15 , and $45 \mathrm{~min}$ ). As shown in Table 3 , the experimental surface coverage was successfully reproduced by the simulation. In this context, the cocrystallization of the open- and the closed ring isomers into ordering $\beta$ is further supported by the simulation considering the total concentration $[\mathbf{1 0}+\mathbf{1 c}]$.
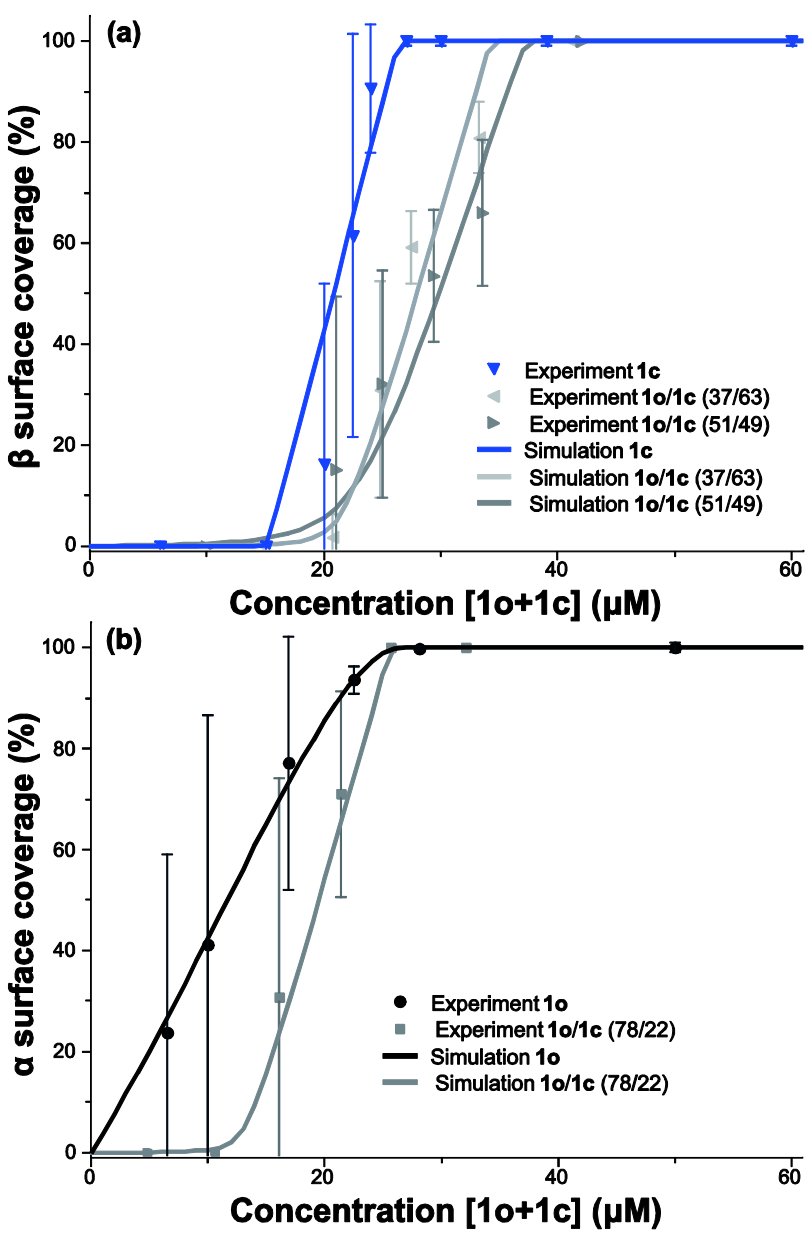

Figure 7. Concentration dependence of the surface coverage of (a) ordering $\beta$ for $1 \mathrm{c}$ and mixtures of $10 / 1 \mathrm{c}(37 / 63$ and $51 / 49)$, and (b) that of ordering $\alpha$ for 10 and a mixture of $10 / 1 \mathrm{c}(78 / 22)$ against total concentration of the two isomers $[10+1 c]$.

Table 2 Best-fitting adsorption parameters for 1o/1c solutions considering [10 $+1 \mathrm{c}]$ (bi-component parameters) $^{a}$

\begin{tabular}{cccccc} 
Ratio1o/1c & $0 / 100$ & $37 / 63$ & $51 / 49$ & $78 / 22$ & $100 / 0$ \\
\hline Ordering & $\beta$ & $\beta$ & $\beta$ & $\alpha$ & $\alpha$ \\
$K_{\mathrm{e}}\left(\mathrm{M}^{-1}\right)$ & $6.6 \times 10^{4}$ & $4.4 \times 10^{4}$ & $3.9 \times 10^{4}$ & $7.2 \times 10^{4}$ & $6.8 \times 10^{4}$ \\
$K_{\mathrm{n}}\left(\mathrm{M}^{-1}\right)$ & $6.6 \times 10^{-2}$ & $2.3 \times 10^{1}$ & $1.9 \times 10^{2}$ & $4.3 \times 10^{1}$ & $6.4 \times 10^{4}$ \\
$\sigma$ & $\leq 10^{-6}$ & $5.2 \times 10^{-4}$ & $4.9 \times 10^{-3}$ & $6.0 \times 10^{-4}$ & 0.95 \\
\\
${ }^{a}$ simulated by the cooperative model on 2-D surface
\end{tabular}

${ }^{a}$ simulated by the cooperative model on $2-D$ surface

Table 3 Experimental surface coverage for the pre-irradiation experiment and simulated values considering a mixing of 10 and $1 \mathrm{c}$ in the ordering $\alpha$ and $\beta^{a}$

\begin{tabular}{|c|c|c|c|c|c|c|c|c|c|c|}
\hline \multirow[b]{2}{*}{ Time $(\min )^{b}$} & \multicolumn{4}{|c|}{ Concentration $^{c}$} & \multicolumn{3}{|c|}{ Surface coverage (experimental data) ${ }^{d}$} & \multicolumn{3}{|c|}{ Surface coverage $(\text { simulated })^{e}$} \\
\hline & [10] $(\mu \mathrm{M})$ & {$[1 \mathrm{c}](\mu \mathrm{M})$} & [1a] $(\mu \mathrm{M})$ & $10 / 1 c$ & $\theta_{\alpha, \exp }$ & $\theta_{\beta, \exp }$ & $\theta_{Y, \exp }$ & $\theta_{\alpha, \operatorname{sim}^{f}}$ & $\theta_{\beta, \text { sim }^{g}}$ & $\theta_{Y, \text { sim }}{ }^{h}$ \\
\hline 5 & 9.4 & 16.1 & 1.8 & $37 / 63$ & 0 & 0.35 & 0 & 0 & 0.31 & 0.09 \\
\hline 15 & 7.8 & 14.9 & 3.9 & $34 / 66$ & 0 & 0.18 & 0.32 & 0 & 0.14 & 0.26 \\
\hline 45 & 5.1 & 9.5 & 11.3 & $35 / 65$ & 0 & 0.005 & 0.79 & 0 & 0.003 & 0.87 \\
\hline
\end{tabular}

${ }^{a}$ Corresponding STM images are shown in Fig. $5 .{ }^{b}$ Time of irradiation with UV light $\left(\lambda_{\text {irrad }}=365 \mathrm{~nm}\right) .{ }^{\circ}$ Concentration of samples was determined by UV-vis. spectroscopy before the deposition on HOPG surface. ${ }^{d}$ Experimental fractional surface coverage observed by STM measurements. ${ }^{e}$ Simulated by the cooperative model using the adsorption parameters based on the total concentration of the two isomers [1o $+1 \mathrm{c}]$ (see Table 2 ). ${ }^{f}$ Values obtained assuming $K_{\mathrm{e}}=0$ since no ordering was experimentally observed in the condition of the ratio of the two isomers $10 / 1 \mathrm{c} .{ }^{9}$ Values obtained using bi-component parameters $\left(K_{\mathrm{e}}=4.4 \times 10^{4} \mathrm{M}^{-1}\right.$, $\left.\sigma=5 \times 10^{-4}\right)$. "Values obtained using mono-component parameters $\left(K_{\mathrm{e}}=1.5 \times 10^{6} \mathrm{M}^{-1}, \sigma=10^{-6}\right)$. 
Although we carefully investigated high-resolution STM images of the cocrystallized orderings, no significant difference has been observed at this time between ordering a obtained from a pure solution of 10 (Figure $8 \mathrm{a}$ ) and from a mixed solution 10/1c (Figure $8 b$ ). It was the same for ordering $\beta$ obtained from a pure solution of 1c (Figure 8c) and from a mixed solution 10/1c (Figure 8d). Owing to a rapid exchange of components during adsorption/desorption equilibrium at the $\mathrm{OA} / \mathrm{HOPG}$ interface, clear distinction of the two isomers at single-molecule resolution may be difficult under ambient conditions.
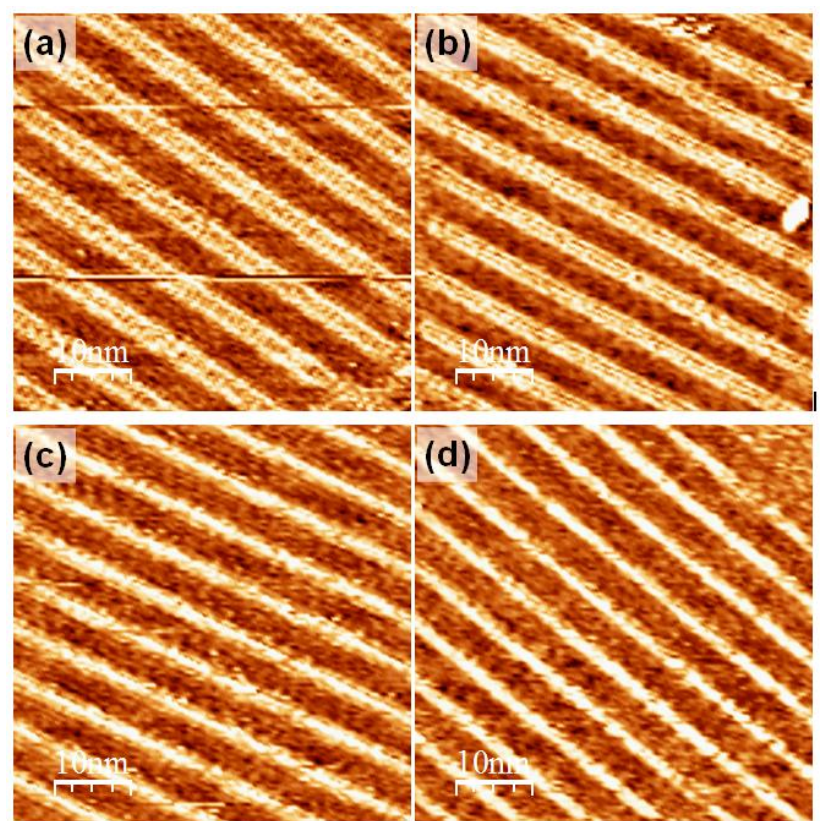

Figure 8. High-resolution STM images $\left(50 \times 50 \mathrm{~nm}^{2}, I_{\text {set }}=10 \mathrm{pA}, V_{\text {bias }}=-1.0\right.$ V) of $(a)$ ordering $\alpha$ for pure $10([10]=16.9 \mu \mathrm{M})$ and $(b)$ for the sample with $\mathbf{1 0} / \mathbf{1 c}=78 / 22([\mathbf{1 0}+\mathbf{1 c}]=16.1 \mu \mathrm{M})(\mathrm{c})$ That of ordering $\beta$ for pure $1 \mathrm{c}([\mathbf{1 c}]=$ $24 \mu \mathrm{M})$ and $(\mathrm{d})$ for the sample with 1o/1c $=37 / 63([10+1 \mathrm{c}]=27 \mu \mathrm{M})$.

\section{Real-time in-situ irradiation}

Next, photochemical interchanges between orderings upon insitu photoirradiation were directly monitored by a real-time STM scanning (Figure 9). Contrary to our expectation, the observed interchanges between orderings were different from that observed from the pre-irradiation experiment shown in Figure 5. STM images were continuously scanned at almost the same position on the substrate for $2 \mathrm{~h}$ (cf. cross mark on Figure 9). After observation of the first STM image of the open-ring isomer $10(t=0 \mathrm{~min})$, the surface was constantly irradiated with UV light (365 nm) without stopping STM scans. In the initial image, several domains of ordering a were observed. Upon UV irradiation, the surface coverage of ordering $\alpha$ was gradually decreased (12 min) until it was completely disappeared (59 min). In the meantime, several small domains of ordering $\mathrm{\gamma}$, composed of the annulated isomer 1a, appeared (14 min). These domains enlarged like a crystal growth (28 $\mathrm{min})$ and eventually covered the substrate almost dominantly (38 min -1 h $21 \mathrm{~min})$.
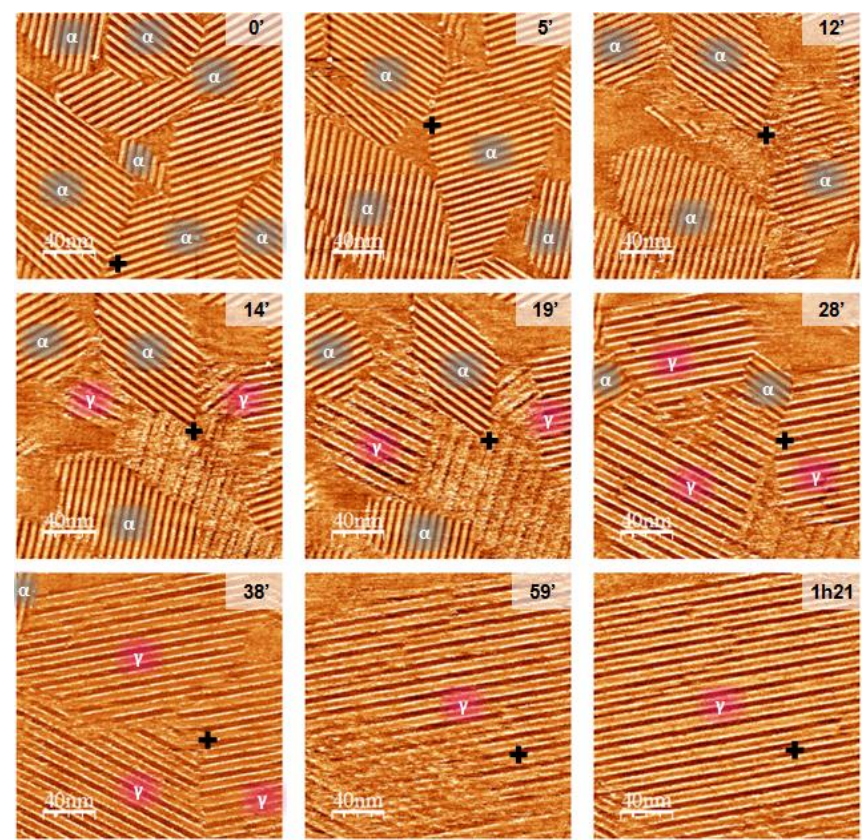

Figure 9. STM images $\left(200 \times 200 \mathrm{~nm}^{2}\right)$ of the in-situ photoirradiation of 10 at the OA/HOPG interface $\left(I_{\text {set }}=10 \mathrm{pA}, V_{\text {bias }}=-1.0 \mathrm{~V},[10]_{t=0} \sim 30 \mu \mathrm{M}\right)$.

According to the simulated evolution of concentrations (Figure 3 and S7 in Supporting Information), the closed-ring isomer 1c was expected to be predominant in the early stage of the irradiation. However, ordering $\beta$ was never observed during the course of the in-situ irradiation. The favourable appearance of ordering $\mathrm{y}$ upon UV irradiation on the surface is consistent with the previously reported result. ${ }^{[32]}$ In the pre-irradiation experiment (Figure 5), the isomers with different ratios of 10/1c can start to adsorb on an empty surface. On the other hand, in the in-situ irradiation experiment (Figure 9), the surface is already almost fully occupied by ordering $\alpha$. We suppose that the closed-ring isomer 1c, produced during the in-situ irradiation, was progressively included in the pre-organized ordering $\alpha$. Therefore, the kinetically metastable ordering $\alpha$, composed of the two isomers $\mathbf{1 0}$ and 1c, was constantly observed until it was replaced by the more stable ordering $\mathrm{y}$ having higher affinity for the HOPG surface.

\section{Conclusions}

In this work, concentration dependence of surface coverage and photochemical interchanges between molecular orderings for the three isomers of a diarylethene were carefully investigated by UV-vis. spectroscopy and STM measurements. Adsorption parameters were determined using a cooperative equilibrium model on 2-D surface for pure 10, 1c and 1a. According to these mono-component parameters, the open-ring isomer 10 showed an isodesmic process $(\sigma \sim 1)$ whereas the closed-ring isomer 1c showed a highly cooperative process $\left(\sigma \leq 10^{-6}\right)$. The annulated isomer 1a showed a very high affinity for HOPG surface $\left(K_{\mathrm{e}} \geq\right.$ 
$10^{6}$ ). Careful inspections on the bi-component system of $\mathbf{1 0}$ and 1c suggested that the two isomers influence each other during the formation of molecular orderings and form mixed crystals. Moreover, mixing-induced cooperativity in ordering formation process was observed by the STM measurements: the closedring isomer 1c can induce cooperativity in the formation of ordering a that is mainly composed of the open-ring isomer 10 . The results presented in this work provide a better understanding of mixing of components in a molecular ordering and photoinduced interchanges between orderings occurring at the liquid/solid interface.

\section{Experimental Section}

General Methods. Reagents and solvents were obtained from commercial suppliers and used without further purification. 1,2-bis(2methyl-5-bromothiophene-3-yl)hexafluorocyclopentene and $\mathrm{N}$-hexadecyl4-iodobenzamide were prepared according to methods reported in the literature. ${ }^{[32,38]}$ All reactions were monitored by thin-layer chromatography carried out on $0.2 \mathrm{~mm}$ Merck silica gel plates (60F-254). Column chromatography was performed on silica gel (Nakarai Tesque, 70-230 mesh). ${ }^{1} \mathrm{H}$ and ${ }^{13} \mathrm{C}$ NMR spectra were recorded on a JEOL JNMALPHA500 or JNM-ECA600 instruments. Proton chemical shifts are reported in ppm downfield from tetramethylsilane (TMS). Carbon chemical shifts are reported in ppm by reference to solvent signal. Mass spectra were obtained by a Thermo Scientific Exactive mass spectrometer ESI-Orbitrap.

Synthesis of the open-ring isomer 10. To a solution of 1,2-bis(2methyl-5-bromo-3-thienyl)hexafluorocyclopentene $(200 \mathrm{mg}, 0.380 \mathrm{mmol})$ in dry THF $(15 \mathrm{~mL})$ at $-78^{\circ} \mathrm{C}$, under nitrogen atmosphere, was added $n$ BuLi (1.6 M in hexane, $0.60 \mathrm{ml}, 0.96 \mathrm{mmol})$. The resulting mixture was stirred for $1 \mathrm{~h}$ at $-78{ }^{\circ} \mathrm{C}$. Then tributyl borate $(0.30 \mathrm{~mL}, 1.1 \mathrm{mmol})$, was added. The solution was warmed up to room temperature and stirred for $3 \mathrm{~h}$. Then $\mathrm{N}$-hexadecyl-4-iodobenzamide $(358 \mathrm{mg}, 0.759 \mathrm{mmol})$ and aq $\mathrm{K}_{2} \mathrm{CO}_{3}(20 \mathrm{wt} \%, 15 \mathrm{~mL}$ ) were added. After Argon was bubbled through the solution, $\mathrm{Pd}\left(\mathrm{PPh}_{3}\right)_{4}$ was added and the solution was refluxed for $16 \mathrm{~h}$ under Argon atmosphere. After cooling down it was washed with aq. $\mathrm{NH}_{4} \mathrm{Cl}$ and extracted with diethyl ether. Organic layers were collected, dried over $\mathrm{MgSO}_{4}$, filtrated and concentrated under vacuum. Purified by silica gel chromatography eluted with chloroform. A white-blue powder. Yield : $94 \%$ (378 mg). ${ }^{1} \mathrm{H}$ NMR $\left(500 \mathrm{MHz}, \mathrm{CDCl}_{3}\right) \delta(\mathrm{ppm}): 7.71$ (d, $J=$ $8.6 \mathrm{~Hz}, 2 \mathrm{H}), 7.58(\mathrm{~d}, J=8.6 \mathrm{~Hz}, 2 \mathrm{H}), 7.34(\mathrm{~s}, 2 \mathrm{H}), 6.13-6.10(\mathrm{~m}, 2 \mathrm{H})$ 3.49-3.44 (m, 4H), $1.99(\mathrm{~s}, 6 \mathrm{H}), 1.64-1.61(\mathrm{~m}, 4 \mathrm{H}), 1.40-1.26(\mathrm{~m}, 52 \mathrm{H})$, $0.88(\mathrm{t}, J=7.0 \mathrm{~Hz}, 6 \mathrm{H}) ;{ }^{13} \mathrm{C}$ NMR $\left(151 \mathrm{MHz}, \mathrm{CDCl}_{3}\right) \delta(\mathrm{ppm}): 166.90$, $142.53,141.31,136.17,134.14,127.88,126.23,125.65,123.60,40.42$, $32.13,29.89,29.86,29.80,29.77,29.57,29.55,27.24,22.89,14.83$, 14.32; UV-vis (Octanoic Acid) $\lambda_{\max }, \mathrm{nm}\left(\varepsilon, \mathrm{M}^{-1} \mathrm{~cm}^{-1}\right)$ : 311 (46 900); HRESI-MS $(\mathrm{m} / \mathrm{z})[\mathrm{M}+\mathrm{H}]^{+}$calcd for $\mathrm{C}_{61} \mathrm{H}_{84} \mathrm{~F}_{6} \mathrm{~N}_{2} \mathrm{O}_{2} \mathrm{~S}_{2} \mathrm{H}^{+}$, 1055.5951; found: 1055.5948.

Synthesis of the closed-ring isomer 1c. A solution of $10(20 \mathrm{mg})$ in ethyl acetate $(200 \mathrm{~mL})$ was irradiated with a UV light $(\lambda=313 \mathrm{~nm})$ for $1 \mathrm{~h}$. Compound 1c was purified by HPLC (Mightysil Si60 250-20, eluted with dichloromethane/EtOAc 90/10, $5.0 \mathrm{~mL} / \mathrm{min}$, retention time $19 \mathrm{~min})$. A blue solid. Yield $72 \%$ (14.4 mg). ${ }^{1} \mathrm{H}$ NMR $\left(500 \mathrm{MHz}, \mathrm{CDCl}_{3}\right) \delta(\mathrm{ppm}): 7.80$ (d, $J=8.6 \mathrm{~Hz}, 4 \mathrm{H}), 7.61(\mathrm{~d}, J=8.6 \mathrm{~Hz}, 4 \mathrm{H}), 6.73(\mathrm{~s}, 2 \mathrm{H}), 6.20-6.16(\mathrm{~m}, 2 \mathrm{H})$, 3.49-3.45 (m, 4H), $2.20(\mathrm{~s}, 6 \mathrm{H}), 1.68-1.61(\mathrm{~m}, 4 \mathrm{H}), 1.39-1.26(\mathrm{~m}, 52 \mathrm{H})$ 0.88 (t, $J=7.0 \mathrm{~Hz}, 6 \mathrm{H}) ;{ }^{13} \mathrm{C}$ NMR $\left(151 \mathrm{MHz}, \mathrm{CDCl}_{3}\right) \delta(\mathrm{ppm}): 166.50$, $156.95,149.52,136.54,135.72,127.59,127.22,115.27,66.35,40.51$, $32.15,29.92,29.88,29.82,29.77,29.59,29.54,27.24,25.47,22.91$,
14.34; UV-vis (Octanoic Acid) $\lambda_{\max }, \mathrm{nm}\left(\varepsilon, \mathrm{M}^{-1} \mathrm{~cm}^{-1}\right): 598$ (19 700), 390 (12 000), 377 (12 000), 320 (34 500); HR-ESI-MS ( $/ \mathrm{m} / \mathrm{z})[\mathrm{M}+\mathrm{H}]^{+}$calcd for $\mathrm{C}_{61} \mathrm{H}_{84} \mathrm{~F}_{6} \mathrm{~N}_{2} \mathrm{O}_{2} \mathrm{~S}_{2} \mathrm{H}^{+}$, 1055.5951; found: 1055.5940 .

Synthesis of the annulated isomer 1a. A solution of $10(20 \mathrm{mg})$ in ethyl acetate $(200 \mathrm{~mL})$ was irradiated with UV light $(\lambda=313$ and $365 \mathrm{~nm})$ for $34 \mathrm{~h}(2 \times 17 \mathrm{~h})$. Then it was irradiated with visible light $(\lambda>480 \mathrm{~nm})$ for $17 \mathrm{~h}$. A first purification by HPLC (Mightysil Si60 250-20, eluted with dichloromethane/EtOAc 90/10, $5.0 \mathrm{~mL} / \mathrm{min}$, retention time $12 \mathrm{~min}$ ) was used to remove the largest part of undesired isomers. Another irradiation sequence with visible light $(\lambda>480 \mathrm{~nm})$ was performed for $17 \mathrm{~h}$ Compound 1a was purified by HPLC (Mightysil Si60 250-20, eluted with dichloromethane/EtOAc 90/10, $5.0 \mathrm{~mL} / \mathrm{min}$, retention time $19.5 \mathrm{~min}$ ). A deep purple solid. Yield $17 \%(3.4 \mathrm{mg}) .{ }^{1} \mathrm{H}$ NMR $\left(500 \mathrm{MHz}, \mathrm{CDCl}_{3}\right) \delta$ (ppm): $7.76(\mathrm{~d}, J=8.6 \mathrm{~Hz}, 2 \mathrm{H}), 7.59(\mathrm{~d}, J=8.6 \mathrm{~Hz}, 2 \mathrm{H}), 6.57(\mathrm{~s}, 2 \mathrm{H})$, 6.10-6.07 (m, 2H), 3.47-3.44 (m, 4H), $2.80(\mathrm{~s}, 3 \mathrm{H}), 2.77(\mathrm{~s}, 3 \mathrm{H}) 1.64-1.60$ $(\mathrm{m}, 4 \mathrm{H}), 1.39-1.24(\mathrm{~m}, 52 \mathrm{H}), 0.88(\mathrm{t}, J=7.0 \mathrm{~Hz}, 6 \mathrm{H}) ;{ }^{13} \mathrm{C}$ NMR: Not obtained due to the limited amount of compound; UV-Vis (Octanoic Acid) $\lambda_{\max }, \mathrm{nm}\left(\varepsilon, \mathrm{M}^{-1} \mathrm{~cm}^{-1}\right): 560$ (9 100), 313 (29 100); HR-ESI-MS $(\mathrm{m} / \mathrm{z})[\mathrm{M}+$ $\mathrm{H}]^{+}$calcd for $\mathrm{C}_{61} \mathrm{H}_{84} \mathrm{~F}_{6} \mathrm{~N}_{2} \mathrm{O}_{2} \mathrm{~S}_{2} \mathrm{H}^{+}$, 1055.5951 ; found: 1055.5936 .

Theoretical calculations. The geometrical optimization was carried out at the RB3LYP/6-31g(d) level of theory. Convergence at a local minimum structure was confirmed by no imaginary frequencies on frequency analysis. Successively the optimized local minimum structures were subjected to TD-DFT calculations to obtain 10 excited states from the lowest energy transition at the identical level of theory.

UV-vis. Spectroscopy and Photochemical Reactions. Absorption spectra were measured on a spectrophotometer (HITACHI U-3310). Optical length of the quartz cells were $1 \mathrm{~cm}$. Photoirradiation experiments on HOPG surface were performed by a Keyence UV-400 UV-LED equipped with an optical fiber $\left(0.30 \mathrm{~W} / \mathrm{cm}^{2}, \lambda=365 \mathrm{~nm}\right)$ or a USHIO 500W Xe lamp with a sharp cut filter (UV-29) and bandpass filter (U340) for UV light $\left(0.64 \mathrm{~W} / \mathrm{cm}^{2}, \lambda_{\max }=313 \mathrm{~nm}\right)$, and with sharp cut filters (U-29 and $Y-48)$ for visible light $\left(0.32 \mathrm{~W} / \mathrm{cm}^{2}, \lambda>460 \mathrm{~nm}\right)$.

Scanning Tunneling Microscopy. All STM experiments were performed at room temperature and ambient conditions. The STM images were acquired with an Agilent technologies 5500 scanning probe microscope in the constant current mode. The STM tips were mechanically cut from a $\mathrm{Pt} / \mathrm{Ir}(80 / 20$, diameter $0.25 \mathrm{~mm}$ ) wire. Highly Oriented Pyrolytic Graphite (HOPG) (purchased from the Bruker Co.) was used as substrate. The concentrations of solutions were controlled by UV-vis. A drop of the solution $(8 \mu \mathrm{L})$ was deposited onto freshly cleaved HOPG, the tip was immersed into the solution and images were scanned. Topography images were obtained using the software WSxM. ${ }^{[39]}$

\section{Acknowledgements}

This work was supported by NEXT program (No. GR062), a Grant-in-Aid for Scientific Research on Innovative Areas "photosynergetics" (No. 26107008) from the MEXT, Grant-in-Aid for Young Scientists (B) (No. 25810048) and a Grant-in-Aid for JSPS Fellows (No. 2604341) from the Japan Society for the Promotion of Science (JSPS). D.F. acknowledges the JSPS for a postdoctoral fellowship.

Keywords: Photochromism • Self-assembly • Scanning Tunneling Microscopy $\bullet$ Mixed Crystals $・$ Induced Cooperativity 
[1] J. V. Barth, G. Costantini, K. Kern, Nature 2005, 437, 671-679.

[2] T. Kudernac, S. Lei, J. A. A. W. Elemans, S. De Feyter, Chem. Soc. Rev. 2009, 38, 402-421.

[3] K. S. Mali, J. Adisoejoso, E. Ghijsens, I. De Cat, S. De Feyter, Acc Chem. Res. 2012, 45, 1309-1320.

[4] A. G. Slater (nee Phillips), P. H. Beton, N. R. Champness, Chem. Sci. 2011, 2, 1440-1448.

[5] A. G. Slater, L. M. A. Perdigão, P. H. Beton, N. R. Champness, Acc. Chem. Res. 2014, 47, 3417-3427.

[6] L. Piot, A. Marchenko, J. Wu, K. Müllen, D. Fichou, J. Am. Chem. Soc. 2005, 127, 16245-16250.

[7] J. Adisoejoso, K. Tahara, S. Okuhata, S. Lei, Y. Tobe, S. De Feyter Angew. Chem., Int. Ed. 2009, 48, 7353-7357.

[8] K. Tahara, H. Yamaga, E. Ghijsens, K. Inukai, J. Adisoejoso, M. O. Blunt, S. De Feyter, Y. Tobe, Nat. Chem. 2011, 3, 714-719.

[9] A. Ciesielski, M. El Garah, S. Haar, P. Kovaříček, J.-M. Lehn, P. Samorì, Nat. Chem. 2014, 6, 1017-1023.

[10] A. G. Slater, Y. Hu, L. Yang, S. P. Argent, W. Lewis, M. O. Blunt, N. R. Champness, Chem. Sci. 2015, 6, 1562-1569.

[11] K. Cui, F. Schlütter, O. Ivasenko, M. Kivala, M. G. Schwab, S.-L. Lee, S. F. L. Mertens, K. Tahara, Y. Tobe, K. Müllen, et al., Chem. Eur. J. 2015, 21, 1652-1659.

[12] Arramel, T. C. Pijper, T. Kudernac, N. Katsonis, M. van der Maas, B. L. Feringa, B. J. van Wees, Nanoscale 2013, 5, 9277-9282.

[13] S. V. Snegir, A. A. Marchenko, P. Yu, F. Maurel, O. L. Kapitanchuk, S. Mazerat, M. Lepeltier, A. Léaustic, E. Lacaze, J. Phys. Chem. Lett. 2011, 2, 2433-2436.

[14] B. Baisch, D. Raffa, U. Jung, O. M. Magnussen, C. Nicolas, J. Lacour, J. Kubitschke, R. Herges, J. Am. Chem. Soc. 2009, 131, 442-443.

[15] C. Dri, M. V. Peters, J. Schwarz, S. Hecht, L. Grill, Nat. Nanotech 2008, 3, 649-653.

[16] L.-P. Xu, L.-J. Wan, J. Phys. Chem. B 2006, 110, 3185-3188.

[17] S. De Feyter, F. C. De Schryver, Chem. Soc. Rev. 2003, 32, 139-150.

[18] S. Lei, K. Tahara, F. C. De Schryver, M. Van der Auweraer, Y. Tobe, S. De Feyter, Angew. Chem., Int. Ed. 2008, 47, 2964-2968.

[19] A. Ciesielski, P. J. Szabelski, W. Rżysko, A. Cadeddu, T. R. Cook, P. J. Stang, P. Samorì, J. Am. Chem. Soc. 2013, 135, 6942-6950.

[20] R. Gutzler, T. Sirtl, J. F. Dienstmaier, K. Mahata, W. M. Heckl, M. Schmittel, M. Lackinger, J. Am. Chem. Soc. 2010, 132, 5084-5090.
[21] M. O. Blunt, J. Adisoejoso, K. Tahara, K. Katayama, M. Van der Auweraer, Y. Tobe, S. De Feyter, J. Am. Chem. Soc. 2013, 135 12068-12075

[22] D. Rohde, C.-J. Yan, H.-J. Yan, L.-J. Wan, Angew. Chem., Int. Ed. 2006, 45, 3996-4000.

[23] Y. Okawa, M. Aono, Nature 2001, 409, 683-684

[24] M. Li, D. den Boer, P. lavicoli, J. Adisoejoso, H. Uji-i, M. Van der Auweraer, D. B. Amabilino, J. A. A. W. Elemans, S. De Feyter, J. Am. Chem. Soc. 2014, 136, 17418-17421.

[25] A. Miura, S. De Feyter, M. M. S. Abdel-Mottaleb, A. Gesquière, P. C. M. Grim, G. Moessner, M. Sieffert, M. Klapper, K. Müllen, F. C. De Schryver, Langmuir 2003, 19, 6474-6482.

[26] M. Blunt, X. Lin, M. del C. Gimenez-Lopez, M. Schroder, N. R Champness, P. H. Beton, Chem. Commun. 2008, 2304-2306.

[27] S. Furukawa, K. Tahara, F. C. De Schryver, M. Van der Auweraer, Y. Tobe, S. De Feyter, Angew. Chem , Int Ed. 2007, 46, 2831-2834.

[28] M. Irie, Chem. Rev. 2000, 100, 1685-1716.

[29] K. Matsuda, M. Irie, J. Photochem. Photobiol. C 2004, 5, 169 - 182

[30] M. Irie, T. Fukaminato, K. Matsuda, S. Kobatake, Chem. Rev. 2014 114, 12174-12277.

[31] R. Arai, S. Uemura, M. Irie, K. Matsuda, J. Am. Chem. Soc. 2008, 130 9371-9379.

[32] For preliminary work without cooperativity analysis see: T. Sakano, $Y$ Imaizumi, T. Hirose, K. Matsuda, Chem. Lett. 2013, 42, 1537-1539.

[33] M. Irie, T. Lifka, S. Kobatake, N. Kato, J. Am. Chem. Soc. 2000, 122, 4871-4876.

[34] M. Irie, T. Lifka, K. Uchida, S. Kobatake, Y. Shindo, Chem. Commun. 1999, 747-750.

[35] D. Zhao, J. S. Moore, Org. Biomol. Chem. 2003, 1, 3471-3491.

[36] T. F. A. De Greef, M. M. J. Smulders, M. Wolffs, A. P. H. J. Schenning R. P. Sijbesma, E. W. Meijer, Chem. Rev. 2009, 109, 5687-5754

[37] S. Yokoyama, T. Hirose, K. Matsuda, Chem. Commun. 2014, 50, 5964-5966.

[38] T. Saika, M. Irie, T. Shimidzu, J. Chem. Soc., Chem. Commun. 1994 2123-2124.

[39] I. Horcas, R. Fernández, J. M. Gómez-Rodríguez, J. Colchero, J. Gómez-Herrero, A. M. Baro, Rev. Sci. Instrum. 2007, 78, 013705. 


\section{Entry for the Table of Contents}

\section{FULL PAPER}

Let's be cooperative! Adsorption process at the octanoic acid/highly oriented pyrolytic graphite interface was investigated for three isomers of a diarylethene derivative. The formation of mixed crystals on 2-D surface and "mixing-induced cooperativity" were highlighted thanks to a cooperative model. Thus a better understanding of photochemical interchanges at the interface became possible.

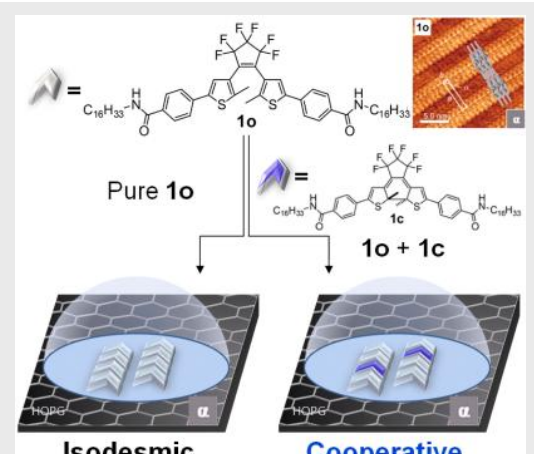

Denis Frath, Takeshi Sakano, Yohei Imaizumi, Soichi Yokoyama, Takashi Hirose and Kenji Matsuda*

Page No. - Page No.

Diarylethene Self-Assembled Monolayers: Cocrystallization and "Mixing-Induced Cooperativity" Highlighted by Scanning Tunneling Microscopy at the Liquid/Solid Interface
Cooperative 